\title{
Ação de extratos aquoso e etanólico de espécies vegetais na germinação de sementes de Brachiaria decumbens Stapf.
}

\section{Effects of aquous and ethanolic extracts of vegetal species on seed germination of Brachiaria decumbens Stapf.}

\author{
José Roberto Pinto de Souza ${ }^{*}$; Luiz Henrique Ilkiu Vidal²; \\ Ricardo Augusto Gorne Viani ${ }^{2}$
}

\begin{abstract}
Resumo
O objetivo do experimento foi avaliar o efeito dos extratos aquoso e etanólico de espécies medicinais sobre germinação de sementes de $B$. decumbens. O delineamento experimental foi inteiramente casualizado com 19 tratamentos ( 9 extratos aquosos, 9 extratos etanólicos e 1 testemunha com água deionizada) com quatro repetições. As espécies e as partes das plantas utilizadas para a obtenção dos extratos foram Baccharis trimera (caule), Baccharis articulata (caule), Canna denudata (folhas), Cymbopogom citratus (folhas), Eucalyptus citriodora (folhas), Lippia alba (folhas e ramos), Momordica charantia (folhas, ramos, flores, frutos e sementes), Ocimum gratissimum (folhas, ramos e flores) e Ruta graveolens (folhas e ramos). A remoção dos extratos vegetais foi realizada por via aquosa e etanólica nas concentrações de $10 \%$ e $1 \%$, respectivamente. As sementes foram imersas nos extratos aquoso e etanólico, e água, por uma hora, e após este tempo semeadas em caixas plásticas. Em seguida, foram colocadas em câmara de germinação climatizada, tipo BOD com 16 horas de escuro $/ 20^{\circ} \mathrm{C}$ e 8 horas de luz $/ 35^{\circ} \mathrm{C}$. As avaliações foram realizadas ao $7^{\circ} \mathrm{e} 21^{\circ}$ dia após a semeadura (DAS). Os métodos de extração afetaram a germinação das sementes. $\mathrm{O}$ uso de extrato tipo aquoso resultou em porcentagem de germinação superior ao do etanólico ao $7^{\circ}$ e $21^{\circ} \mathrm{DAS}$. Os extratos vegetais testados não afetaram a germinação.
\end{abstract}

Palavras-Chave: Capim braquiária, alelopatia, plantas medicinais.

\begin{abstract}
The objective of this study was to evaluate the effects of aquous and ethanolic extracts of medicinal species on seed germination of $B$. decumbens. The experimental design was completely randomized with 19 treatments ( 9 aquous extracts, 9 ethanolic extracts and a check was deionized water) with 4 replicates. The species and organs used to obtain the extracts were Baccharis trimera (shoot), Baccharis articulata (shoot), Canna denudata (leaves), Cymbopogom citratus (leaves), Eucalyptus citriodora (leaves), Lippia alba (leaves and branches), Momordica charantia (leaves, branches, flowers, fruits and seeds), Ocimum gratissimum (leaves, branches and flowers) e Ruta graveolens (leaves and branches). The extracts were obtained by aquous and ethanolic infusions in $10 \%$ and $1 \%$ concentration respectively. The seeds were treated with extracts for one hour and after this time sowed in plastic boxes. They were maintained in germination chamber (BOD) with 16 hours of dark $/ 20^{\circ} \mathrm{C}$ and 8 hours of light $/ 35^{\circ} \mathrm{C}$. The evaluation were made at $7^{\text {Th }}$ and $21^{\text {st }}$ days after seeding (DAS). The extraction methods affected seed germination. The use of aquous extract showed greater germination percentage than the ethanolic one at $7^{\text {Th }}$ and $21^{\text {st }}$ days. The evaluated extracts did not affect the seeds' germination.
\end{abstract}

Key Words: Brachiaria grass, alelopaty, medicinal plants.

\footnotetext{
1 Professor Dr., Departamento de Agronomia, CCA, UEL, C.P. 6001, CEP 86.051-990, Londrina, PR., Tel. 43 3371-4555, E-mail: jose@uel.br

2 Graduando em Agronomia, UEL, CCA, Departamento de Agronomia - Londrina-PR

* Autor para correspondência.
} 


\section{Introdução}

A Brachiaria decumbens Stapf. é uma planta herbácea da família Poaceae (Gramineae), conhecida vulgarmente como capim-braquiária, originária de Uganda e introduzida no Brasil como forrageira (ALCÂNTARA, 1980). Devido a suas características de resistência à seca, ao frio, ao fogo, ao pisoteio e sua fácil adaptação a vários tipos de solo e por ser pouco exigente quanto à fertilidade dos solos, foi bem aceita como uma alternativa para a formação e reforma de pastagens (PUPO, 1979). Com o decorrer do tempo, esta se constituiu também em uma planta invasora agressiva de rápido crescimento (KISSMANN, 1991). Sua propagação pode ser feita por mudas (estolões) ou sementes. As sementes necessitam de um armazenamento de aproximadamente 12 meses antes da semeadura devido à presença de dormência (ALCÂNTARA; BUFARAH, 1980), provocada por restrições às trocas gasosas impostas pela gluma (CARVALHO; NAKAGAWA, 2000). Castro et al. (1996) verificaram que a quebra da dormência de sementes de $B$. decumbens por escarificador elétrico de impacto é mais eficiente que a química $\left(\mathrm{H}_{2} \mathrm{O}_{2}\right)$ e a térmica (água a $70^{\circ} \mathrm{C}$ ).

Atualmente, quando considerada como planta infestante, os principais métodos utilizados para o controle de $B$. decumbens são o mecânico e o químico. A alelopatia é, também, um método que tem sido objeto de estudo para o controle das plantas daninhas.

Estudos do efeito de extratos vegetais sobre a germinação podem ser úteis para diminuir a incidência de plantas daninhas. Tais extratos podem quebrar a dormência das sementes de plantas daninhas facilitando um posterior controle químico.

Os ácidos fenólicos, cumarina, terpenóides, alcalóides, flavonóides, etileno e vários outros compostos têm ação alelopáticas (RICE, 1979).

Souza Filho, Rodrigues e Rodrigues (1996) observaram que o potencial alelopático da parte aérea, de raízes e de sementes do assa-peixe (Vernonia polyanthes Less.) sobre a germinação de sementes e alongamento da radícula de plântulas de Brachiaria humidicola, B. decumbens e Brachiaria brizantha varia conforme a espécie e parte da planta de assapeixe da qual é feito o extrato.

O óleo de Cymbopogon citratus em suspensão aquosa a $10 \%$ de concentração inibiu totalmente a germinação de sementes de Digitaria horizontalis, Sorghum halepense, Bidens pilosa, Euphorbia heterophylla e Raphanus raphanistrum, mas não de Portulaca oleracea (VALARINI; FRIGUETTO; SPADOTTO, 1996).

Extratos vegetais aquosos preparados com material fresco de Duboisia leichhardtii, Baccharis articulata, Erythrina speciosa, Rosmarinus officinalis, Baccharis trimera e Lippia alba, em concentração de $25 \%$ mostraram bons resultados para a quebra da dormência de sementes de $B$. decumbens (AGUILERA, 2000).

Borges, Bonaldo e Cruz (1999) observaram que a aplicação de extratos aquosos de folhas de Eucalyptus citriodora e C. citratus nas concentrações de $30 \%$ inibiram totalmente a germinação de sementes de B. pilosa, enquanto E. citriodora reduziu em $72 \%$ e C. citratus em $53 \%$ a germinação de Sida rhombifolia.

Com base nos fatos expostos, avaliou-se o efeito de extratos aquosos e etanólicos de espécies vegetais de uso medicinal na germinação de sementes de B. decumbens.

\section{Material e Métodos}

As sementes de $B$. decumbens utilizadas no experimento foram selecionadas no laboratório para a obtenção de $100 \%$ de pureza e $65 \%$ de germinação.

Os materiais utilizados para a obtenção dos extratos vegetais aquosos e etanólicos foram coletados no Horto Medicinal, da Universidade Estadual de Londrina, Londrina, às 10:00 h do mês de maio de 2001. As plantas foram colocadas em estufa de circulação forçada de ar à temperatura de $35^{\circ} \mathrm{C}$ até atingir a secagem completa. Após a secagem, as plantas foram 
acondicionadas em sacos de papel identificados e mantidos em condições de ambiente controlado.

O delineamento experimental foi inteiramente casualizado com os tratamentos dispostos em arranjo fatorial $(2 \times 9)$ sendo 2 tipos de extratos (aquoso e etanólico) e 9 espécies medicinais, mais 1 testemunha (com água deionizada) com quatro repetições. As nove espécies vegetais escolhidas e as partes das plantas utilizadas para a obtenção dos extratos foram: Baccharis trimera Less. (caule), Baccharis articulata (Lam.) Person. (caule), Canna denudata Roscoe (folhas), Cymbopogom citratus (D. C.) Stapf. (folhas), Eucalyptus citriodora Hook.(folhas), Lippia alba (Mill) N. E. Brown (folhas e ramos), Momordica charantia L. (folhas, ramos, flores, frutos e sementes), Ocimum gratissimum L. (folhas, ramos e flores) e Ruta graveolens L. (folhas e ramos).

Os extratos aquosos foram obtidos com a trituração de $50 \mathrm{~g}$ de material seco de cada espécie em $500 \mathrm{~mL}$ de água deionizada. Estes extratos foram deixados em repouso por $24 \mathrm{~h}$ em condições naturais, e após este período foram filtrados e coletados num Becker. Posteriormente, repassados para frascos de vidro âmbar identificados e mantidos em geladeira até o momento de serem utilizados.

Para o preparo dos extratos etanólicos, os materiais foram picados com tesoura e imersos em etanol durante 15 dias em ambiente fechado. Após este período, os materiais foram filtrados e encaminhados para evaporadores rotativos à vácuo para efetuar a separação do álcool do extrato vegetal à temperatura entre 80 e $90^{\circ} \mathrm{C}$. Em seguida, os extratos obtidos foram colocados em estufa com circulação forçada de ar a $40^{\circ} \mathrm{C}$ durante dois dias para evaporar o etanol ainda presente. O etanol recuperado do evaporador foi colocado novamente em contato com cada material vegetal para uma segunda extração durante sete dias. Em seguida, realizaram-se os mesmos procedimentos da primeira extração. Os extratos vegetais obtidos foram mantidos em congelador até o momento da utilização.

As sementes de B. decumbens foram imersas nos extratos aquoso e etanólico por uma hora, e a testemunha em água deionizada. $\mathrm{O}$ teste de germinação foi realizado com quatro subamostras de 100 sementes cada uma, semeadas sobre papel substrato especial para germinação em caixas plásticas, e em seguida colocados em germinador tipo BOD com controle de fotoperíodo e alternância de temperatura $\left(16\right.$ horas escuro $/ 20^{\circ} \mathrm{C}$ e 8 horas de luz $\left./ 35^{\circ} \mathrm{C}\right)$. As avaliações foram feitas aos 7 e 21 dias após a semeadura. Os resultados de germinação foram expressos em porcentagem de plantas normais, que emitiram radícula e primórdios foliares (BRASIL, 1992).

Os dados de porcentagem de germinação foram transformados em arc sen raiz quadrada (X/100) para a realização da análise de variância, e a comparação entre as médias foi realizada pelo teste de Tukey a $5 \%$.

\section{Resultados e Discussão}

Não houve interação significativa entre os fatores estudados. Os métodos de extração interferiram na germinação. $\mathrm{O}$ extrato tipo aquoso apresentou porcentagem de germinação significativamente maior que o tipo etanólico ao $7^{\circ}$ e $21^{\circ}$ DAS (Tabela 1). O processo de extração etanólica proporcionou, provavelmente, maior concentração ou presença de princípios ativos que a extração aquosa. 
Tabela 1 - Porcentagem de germinação de Brachiaria decumbens tratada com extratos vegetais aquoso e etanólico ao $7^{\circ}$ e $21^{\circ}$ DAS. LondrinaPR, 2001.

\begin{tabular}{ccc}
\hline Extrato Vegetal & $7^{\circ}$ DAS & $21^{\circ}$ DAS \\
\hline Aquoso & $40,86 \mathrm{a}$ & $68,19 \mathrm{a}$ \\
Etanólico & $35,94 \mathrm{~b}$ & $53,56 \mathrm{~b}$ \\
\hline C.V. $\%$ & 13,89 & 9,61 \\
\hline
\end{tabular}

Médias seguidas de mesma letra na coluna não diferem entre si pelo Teste de Tukey à $5 \%$.

Não houve diferença significativa de germinação das sementes de $B$. decumbens com a aplicação dos extratos vegetais (aquoso ou etanólico) (Tabela 2). Estes resultados se contrapõem aos obtidos por Aguilera (2000) que verificou a quebra da dormência de sementes de $B$. decumbens com a aplicação de extratos aquosos de Baccharis trimera, Baccharis articulata, Rosmarinus officinalis, Datura stramonium, Lippia alba, Cymbopogon citratus, Cymbopogon nardus, Ruta graveolens, Ocimum gratissimum, Tropaelum majus, Duboisia lichhardtii e Erytrina speciosa, na concentração de $25 \%$.

A literatura sobre o assunto apresenta algumas contradições, como o emprego do óleo de Cymbopogon citratus em suspensão aquosa a $10 \%$ inibindo totalmente a germinação de sementes de Digitaria horizontalis, Sorghum halepense, Bidens pilosa, Euphorbia heterophylla e Raphanus raphanistrum, e não de Portulaca oleracea (VALARINI; FRIGUETTO; SPADOTTO, 1996). Os trabalhos de Souza Filho, Rodrigues e Rodrigues (1996) constataram a inibição da germinação de sementes e alongamento da radícula de plântulas de $B$. decumbens com a aplicação de extrato aquoso de Vernonia polyanthes à $10 \%$.
Tabela 2 - Porcentagens de germinação de sementes de Brachiaria decumbens com a aplicação de diferentes extratos vegetais ao $7^{\circ}$ e $21^{\circ}$ DAS. Londrina-PR, 2001.

\begin{tabular}{lcc}
\hline \multicolumn{1}{c}{ Espécie } & $7^{\circ} \mathrm{DAS}$ & $21^{\circ} \mathrm{DAS}$ \\
\hline Baccharis articulata & $36,12 \mathrm{a}$ & $58,50 \mathrm{a}$ \\
Baccharis trimera & $46,00 \mathrm{a}$ & $67,00 \mathrm{a}$ \\
Canna denudata & $31,88 \mathrm{a}$ & $56,75 \mathrm{a}$ \\
Cymbopogom citratus & $37,63 \mathrm{a}$ & $58,75 \mathrm{a}$ \\
Eucalyptus citriodora & $36,00 \mathrm{a}$ & $59,13 \mathrm{a}$ \\
Lippia alba & $39,88 \mathrm{a}$ & $60,88 \mathrm{a}$ \\
Momordica charantia & $39,13 \mathrm{a}$ & $62,50 \mathrm{a}$ \\
Ocimum gratissimum & $41,63 \mathrm{a}$ & $61,63 \mathrm{a}$ \\
Ruta graveolens & $37,38 \mathrm{a}$ & $62,75 \mathrm{a}$ \\
$\mathrm{H}_{2} \mathrm{O}$ & $38,25 \mathrm{a}$ & $62.25 \mathrm{a}$ \\
\hline C.V. $\%$ & 13,89 & 9,61 \\
\hline
\end{tabular}

Médias seguidas de mesma letra na coluna não diferem entre si pelo teste de Tukey à $5 \%$.

Os trabalhos citados comprovam a eficiência das plantas utilizadas como espécies doadoras, e a $B$. decumbens como espécie receptora, que responde aos estímulos das substâncias alelopáticas. O extrato aquoso de Baccharis articulata demonstrou a maior porcentagem de germinação de sementes de $B$. decumbens, tanto no $7^{\circ}$ quanto no $21^{\circ} \mathrm{DAS}$; entretanto, em nenhuma das avaliações realizadas houve o destaque de algum dos tratamentos de forma isolada, e não diferindo significativamente da testemunha.

Comparando-se os valores médios de germinação do presente experimento $\left(29,50 \%\right.$ a 48,50 ao $7^{\circ}$ DAS e $40,50 \%$ a $77,00 \%$ no $21^{\circ}$ DAS) com os de Aguilera (2000) (7,66\% a 22,83\% ao $7^{\circ}$ DAS e $12,2 \%$ a $34,6 \%$ no $21^{\circ} \mathrm{DAS}$ ), nota-se que os valores médios de porcentagem de germinação de sementes de $B$. decumbens são nitidamente superiores. Isto indica que, possivelmente, as sementes utilizadas no presente experimento não apresentavam dormência, mascarando um possível efeito alelopático positivo dos extratos sobre estas. 
Apesar de já existirem trabalhos publicados a respeito do efeito de extratos sobre a germinação de $B$. decumbens, os resultados obtidos com este trabalho indicaram a necessidade de maiores estudos, devido ao grande número de variáveis que podem interferir nos resultados. Entre estas variáveis destacam-se a metodologia de extração, a concentração do extrato, a forma e o tempo de contato do extrato com as sementes.

\section{Conclusões}

A utilização de extrato etanólico reduziu a germinação das sementes de Brachiaria decumbens, em relação ao aquoso.

Os extratos vegetais testados não afetaram a germinação das sementes de Brachiaria decumbens.

\section{Referências}

AGUILERA, D. B. Quebra de dormência de sementes de Brachiaria decumbens Stapf. com extratos de plantas, nitrato de potássio e ácido giberélico. 2000. Dissertação (Mestrado) - Universidade Estadual de Londrina, Londrina.

ALCÂNTARA, P. B.; BUFARAH, G. Plantas forrageiras: gramíneas \& leguminosas. São Paulo: Nobel, 1980,

ALCÂNTARA, P. B. Plantas forrageiras (Gramineas \& Leguminosas). 5.ed. São Paulo: Nobel, 1999.
BORGES, I. M.; BONALDO, S. M.; CRUZ, M. E. S. Efeitos alelopáticos de extratos vegetais medicinais sobre espécies invasoras. In: CONGRESSO SUL BRASILEIRO DE PLANTAS MEDICINAIS, 1., 1999, Maringá. Anais... Maringá: FUEM, 1999. p.46.

BRASIL. Ministério da Agricultura e Reforma Agrária. Regras para a análise de sementes. Brasília: SNDA/ DNDV/CLAV, 1992.

CARVALHO, N. M.; NAKAGAWA, J. Sementes - ciência, tecnologia e produção. In: Dormência de sementes. 4.ed. Jaboticabal: FUNEP, 2000. p.167-223.

CASTRO, R. T. C. et al. Superação de dormência tegumentar em sementes de B. decumbens Stapf. Revista Ceres, Viçosa, v.43, n.245, p.65-75, 1996.

KISSMANN, G. K. Plantas infestantes e nocivas. São Paulo: BASF Brasileira, 1991.

PUPO, N. I. H. Manual de pastagens e forrageiras: formação, conservação e utilização. Campinas: Instituto Campineiro de Ensino Agrícola, 1979.

RICE, E. L. Allelopathy. New York: Academic, 1974.

SOUZA FILHO, A. P. S.; RODRIGUES, L. R. A.; RODRIGUES, T. J. D. Efeitos de extratos aquosos de assa-peixe sobre a germinação de três espécies de braquiária. Planta Daninha, Botucatu, v.14, n.2, p.93101, 1996.

VALARINI, P. J.; FRIGUETTO, R. T. S.; SPADOTTO, C. A. Potencial de uso da erva medicinal Cymbopogon citratus no controle de fitopatógenos do feijoeiro e plantas daninhas em áreas irrigadas. Científica, Jaboticabal, v.24, n.1, p.199-214, 1996. 
